\title{
Perancangan Sistem Informasi Pendaftaran dan Riwayat Pemeriksaan Pasien di Klinik Berbasis Web
}

\author{
Asri Mulyani ${ }^{1}$, Sinta Nurfatonah ${ }^{2}$ \\ Jurnal Algoritma \\ Sekolah Tinggi Teknologi Garut \\ J1. Mayor Syamsu No. 1 Jayaraga Garut 44151 Indonesia \\ Email : jurnal@itg.ac.id \\ 1'asrimulyani@itg.ac.id \\ 21606002@itg.ac.id
}

\begin{abstract}
Abstrak - Kegiatan pendaftaran pasien berupa pencatatan data diri yang dilakukan untuk mempermudah pencarian data yang sudah dicatat dan mempermudah mengenali pasien yang baru mendaftar, sedangkan pemeriksaan riwayat pemeriksaan pasien merupakan hasil diagnosis dari proses pemeriksaan yang dilakukan oleh dokter Kegiatan pencatatan yang masih dilakukan di buku jurnal berdasarkan observasi di Diego Klinik Cihuni menjadikan pertugas yang mencatat harus bertanya tentang pasien yang sudah mendaftar atau belum lalu mencari data dahulu. Penelitian ini bertujuan untuk membuat sistem informasi untuk pendaftaran dan mencatat riwayat pemeriksaan pasien yang bertempat di klinik berbasis web, dimana dalam perancangannya menggunakan Metodologi Unified Sofware Development Process yang terdiri dari beberapa tahapan Analisis, Perancangan, Implementasi Deployment dan Pengujian serta menggunakan Unified Modelling Language untuk pemodelannya dan pengujian, sertamenggunakan blackbox testing untuk tahap pengujian. Penelitian ini menghasilkan aplikasi yang dapat menampilkan informasi seputar pendaftaran dan riwayat pemeriksaan pasien dan mempermudah petugas dalam mengelola pemeriksaan dengan kelengkapan fitur cetak data.
\end{abstract}

Kata Kunci - Pasien; Pemeriksaan; Pendaftaran; Riwayat.

\section{PENDAHULUAN}

Sistem Informasi yaitu perpaduan teratur dari perangkat keras, perangkat lunak, jaringan komunikasi dan sumber daya data yang mengumpulkan, mengubah, dan menyebar informasi dalam sebuah organisasi [1], sistem informasi juga melibatkan peran manusia yang akan mengoperasikan perpaduan teratur diatas [2]. Pendaftaran pasien merupakan salah satu pencatatan data diri guna untuk mengetahui, mempermudah mencari data, dan mencatat riwayat penyakit pasien yang sudah melakukan pemeriksaan dokter. Pencatatan yang masih dilakukan di dalam jurnal rekam medis seringkali memperlambat pencarian data yang merujuk pada nama atau nomor pasien sehingga mempersulit pencarian yang dilakukan oleh petugas pendaftaran jika ada salah penulisan pengejaan nama pasien, sebagaimana halnya dengan Diego Klinik Cihuni diharapkan dapat memaksimalkan pelayanan dari pendaftaran untuk mengefesienkan waktu dan kesalahan informasi tentang data diri pasien, lalu untuk petugas yang mengelola pasien yang menjalani pengobatan jangka panjang dapat mengetahui riwayat pemeriksaan guna untuk mengetahui perkembangan pemeriksaan pasien.

Sebelumnya telah ada beberapa penelitian dengan tema yang sama pertama Rekam Medis Berbasis ClientServer yang penelitiannya dilakukan di cipanas. Penelitian ini bertujuan menghasilkan aplikasi yang memudahkan petugas dalam menyampaikan informasi berbasis client-server [3], penelitian kedua yaitu Penerimaan untuk santri baru di SD Islam Terpadu Persis yang terletak di Tarogong Berbasis Web bertujuan 
memudahkan dan mengefesienkan waktu dalam penerimaan santri yang dilakukan melalui website [4], penelitian ketiga yaitu Pencatatan berupa persediaan obat dengan metodologi berorientasi pada objek yang berada di apotek Nur Gesifa yang bertujuan untuk menghasilkan aplikasi desktop memudahkan dalam pencatatan persediaan obat [5], penelitian keempat yaitu Rekam Medis yang bertempat di Klinik Akper Kesdam II/Sriwijaya Garuda Putih yang bertujuan yaitu menganalisis kebutuhan dalam membangun sistem informasi rekam medis [6] dan penelitian kelima Rekam Medis di Puskesmas Masaran 1 Sragen yang betujuan menghasilkan aplikasi menggunakan SQL Server 2000 [7].

Kelima penelitian ini dijadikan rujukan untuk merancang sebuah sistem pendaftaran pada pasien lalu pengelolaan pendaftaran dan riwayat pemeriksaan pasien yang dapat memudahkan petugas. Merujuk pada kelima penelitian, maka dihasilkan Perancangan Sistem Informasi Pendaftaran dan Riwayat Pemeriksaan Pasien di Klinik Berbasis Web.

\section{METODE PENELITIAN}

Alur kerja Perencanaan penelitian disajikan menggunakan skema WBS yang di tampilkan pada Gambar 1 .

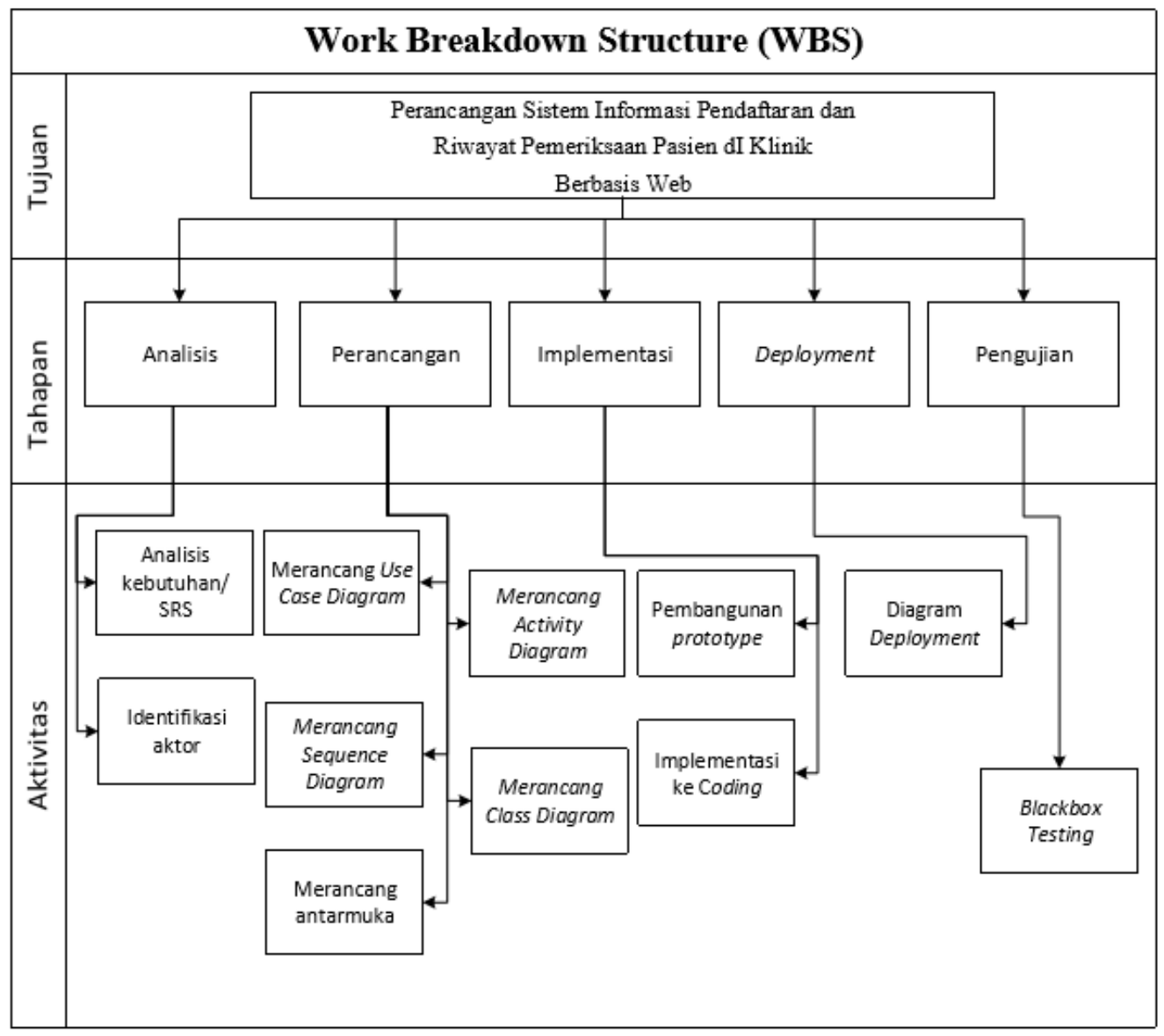

Gambar 1: Work Breakdown Structure

Tahapan-tahapan yang dilalui penelitian berdasarkan metode Unified Software Development Process [8]. adapun penjelasan dari setiap tahapan yang dilaukan secara garis besar adalah sebagi berikut:

1) Analisis

Aktivitas penentuan sistem yang berjalan mengetahui identifikasi masalah yang diperlukan. 
2) Perancangan

Pada tahap perancangan menggunakan pemodelan Unified Modelling Language.

3) Implementasi

Pada tahap implementasi yaitu di mulainya pembangunan prototype aplikasi dan mengimplementasikan coding pada bahasa pemograman $H T M L$ bahasa pemformatan teks untuk dokumen-dokumen pada jaringan komputer [9], PHP dan pembuatan database menggunakan phpMyadmin yang merupakan sebuah aplikasi tidak berbayar bertujuan mempermudah manajemen $M y S Q L$ [10] yang terdapat dalam aplikasi XAMMP sebagai server yang berdiri sendiri terdiri atas program dan penerjemah bahasa yang ditulis kedalam bahasa pemrograman [11].

4) Deployment

Pada tahap Deployment yaitu membuat rancangan diagram deployment untuk mengetahui arsitektur perangkat pendukung yang terhubung dengan sistem.

5) Pengujian

Tahap pengujian yaitu melakukan uji coba terhadap sistem yang telah dirancang menggunakan metode blackbox

\section{HASIL DAN PEMBAHASAN}

\section{Hasil Penelitian}

1) Analisis

a. Proses yang Sedang Berjalan

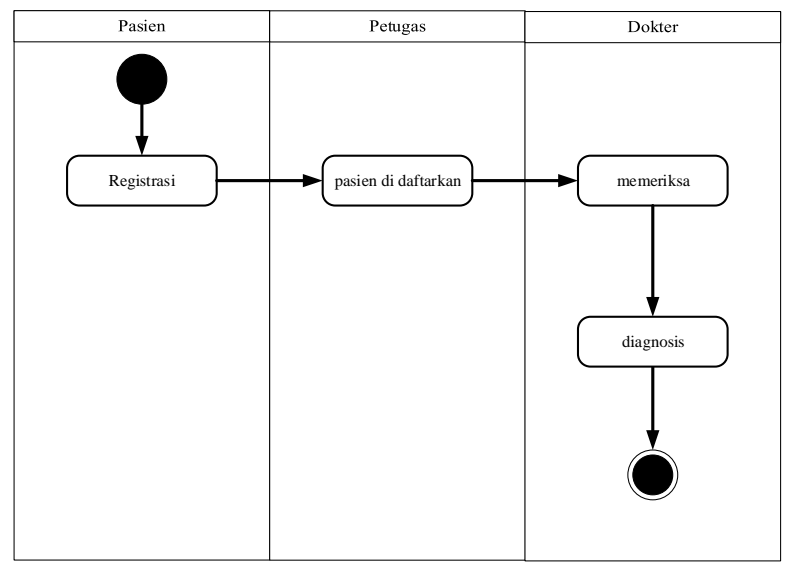

Gambar 2: Proses Yang Sedang Berjalan

b. Identifikasi Aktor

Tabel 1: Identifikasi Aktor

\begin{tabular}{|l|l|ll|}
\hline \multicolumn{1}{|c|}{ Aktor } & \multicolumn{1}{|c|}{ Klasifikasi Aktor } & \multicolumn{2}{|c|}{ Deskripsi } \\
\hline Petugas & $\begin{array}{l}\text { Primary System Actor } \\
\text { (PSA) }\end{array}$ & $\begin{array}{l}\text { a. Melakukan login } \\
\text { b. Melakukan pengelolaan data } \\
\text { pendaftaran, data pasien, data riwayat } \\
\end{array}$ & $\begin{array}{l}\text { pemeriksaan } \\
\text { c. Membuat cetak data }\end{array}$ \\
\hline Admin & $\begin{array}{l}\text { Primary System Actor } \\
\text { (PSA) }\end{array}$ & $\begin{array}{l}\text { Melakukan login } \\
\text { bendaftaran, data pasien, data riwayat }\end{array}$ \\
\hline
\end{tabular}




\begin{tabular}{|c|c|c|}
\hline Aktor & Klasifikasi Aktor & Deskripsi \\
\hline & & $\begin{array}{l}\text { pemeriksaan, data dokter, data } \\
\text { poliklinik, dan data pengguna } \\
\text { c. Membuat cetak data }\end{array}$ \\
\hline Pasien & $\begin{array}{l}\text { Primary Bussines } \\
\text { Actor (PBA) }\end{array}$ & $\begin{array}{l}\text { a. Melakukan login } \\
\text { b. Mengisi pendaftaran }\end{array}$ \\
\hline Dokter & $\begin{array}{l}\text { Primary Bussines } \\
\text { Actor (PBA) }\end{array}$ & $\begin{array}{ll}\text { a. Melakukan login } \\
\text { b. Melihat riwayat pemeriksaan penyakit }\end{array}$ \\
\hline
\end{tabular}

\section{2) Perancangan}

a. Usecase

Use case diterapkan untuk mengetahui fungsi apa saja yang ada di dalam sebuah sistem informasi dan siapa saja yang berhak menggunakan fungsi-fungsi itu [12]. Berdasarkan identifikasi aktor yang akan dibuat sistem informasi pendaftaran dan riwayat pemeriksaan pada pasien di klinik maka use case diagram yang dirancang memiliki empat aktor yaitu pasien yang melakukan pendaftaran diri melalui website, petugas yang dapat mengelola pasien dan riwayat pemeriksaan, dokter yang mengelola pemeriksaan, dan admin yang dapat mmengelola pasien, riwayat pemeriksaan dan mengelola akun pengguna.

b. Activity Diagram

Tahapan ini menjelaskan aktivitas-aktivitas yang dilakukan aktor dengan sistem sebagai berikut

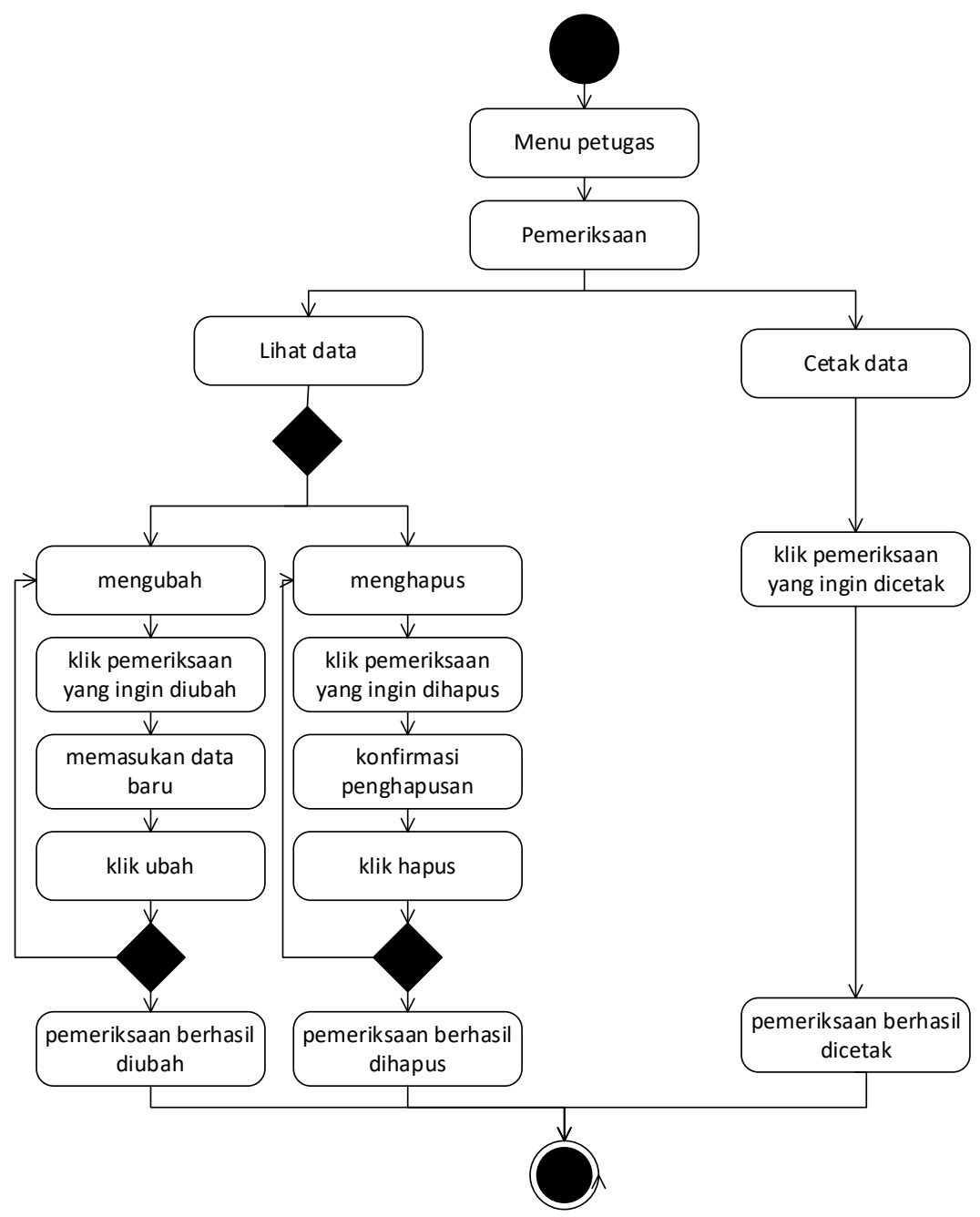

Gambar 3: Pemeriksaan Pasien 


\section{c. Sequence Diagram}

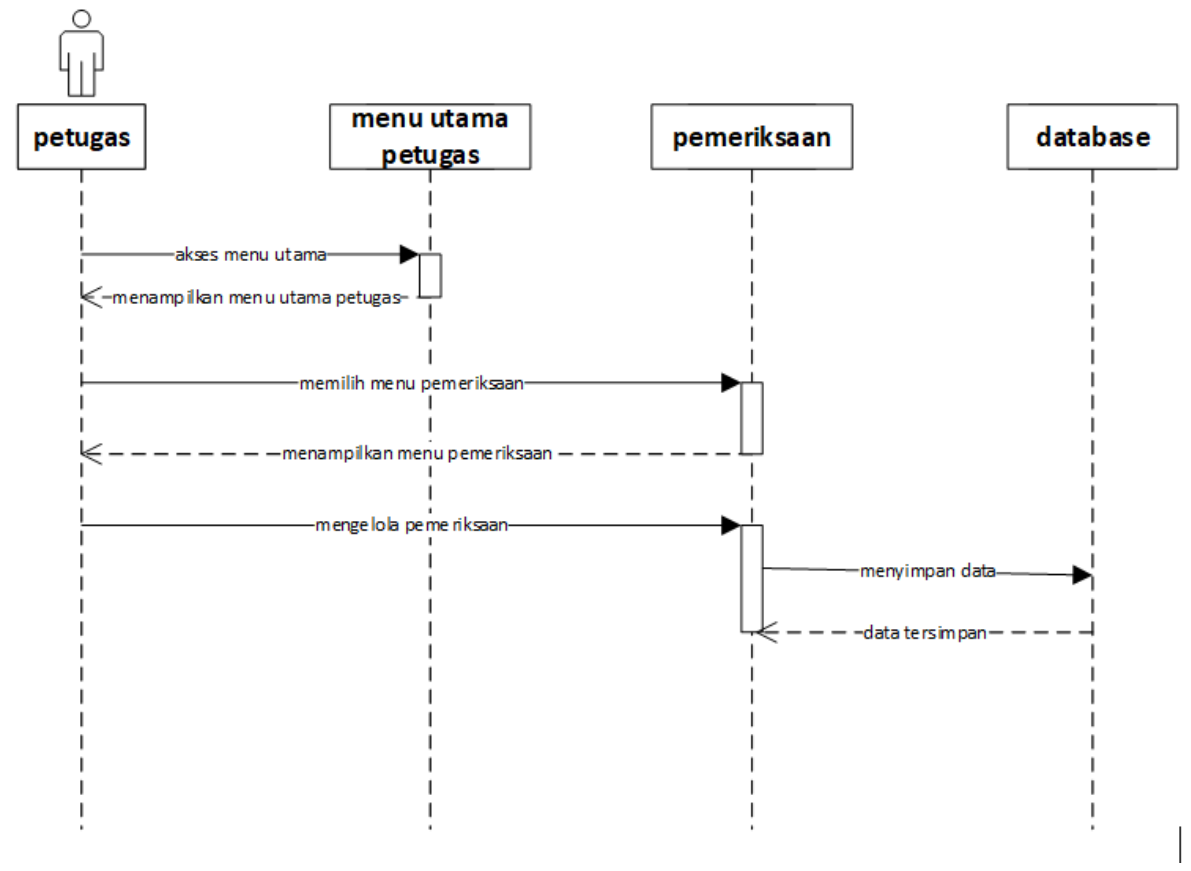

Gambar 4: Sequence Diagram Pemeriksaan

d. Class Diagram

Berikut adalah class diagram aplikasi pendaftaran dan riwayat pemeriksaan pada pasien di klinik.

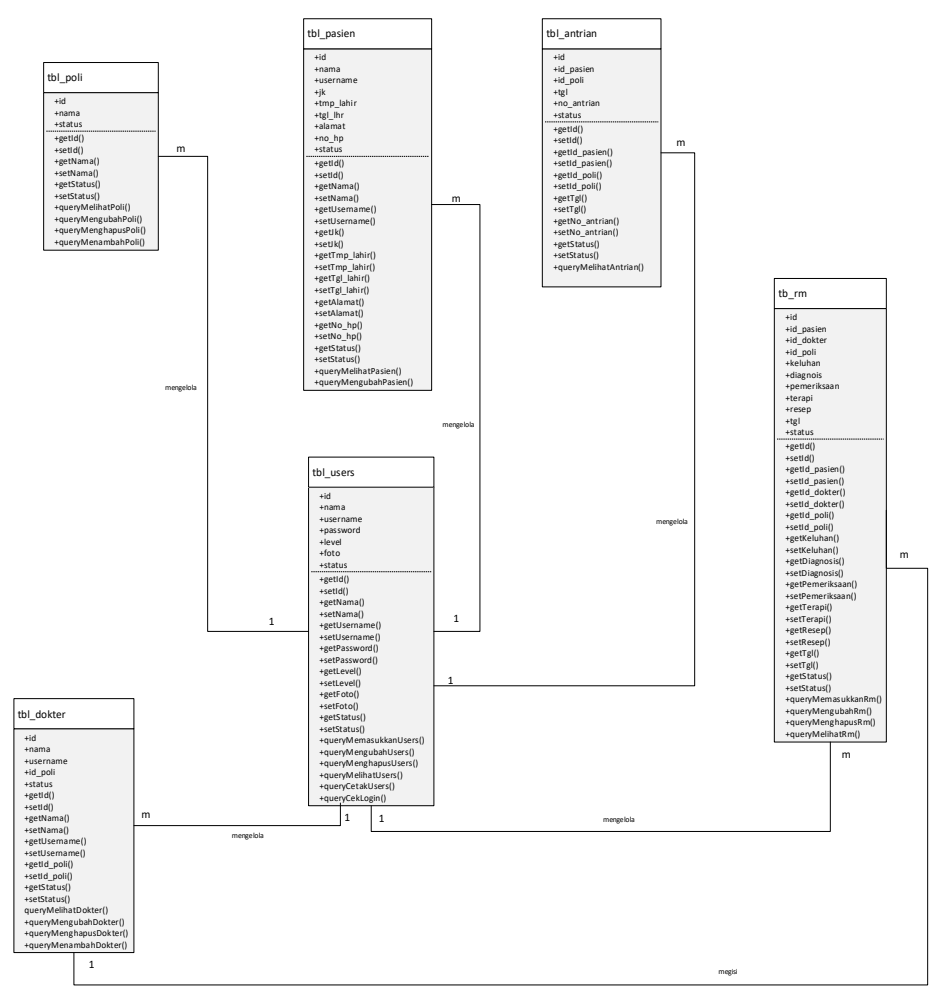

Gambar 5: Class Diagram Pendaftaran dan Riwayat Pemeriksaan Pasien Di Klinik 


\section{e. Stuktur Menu}

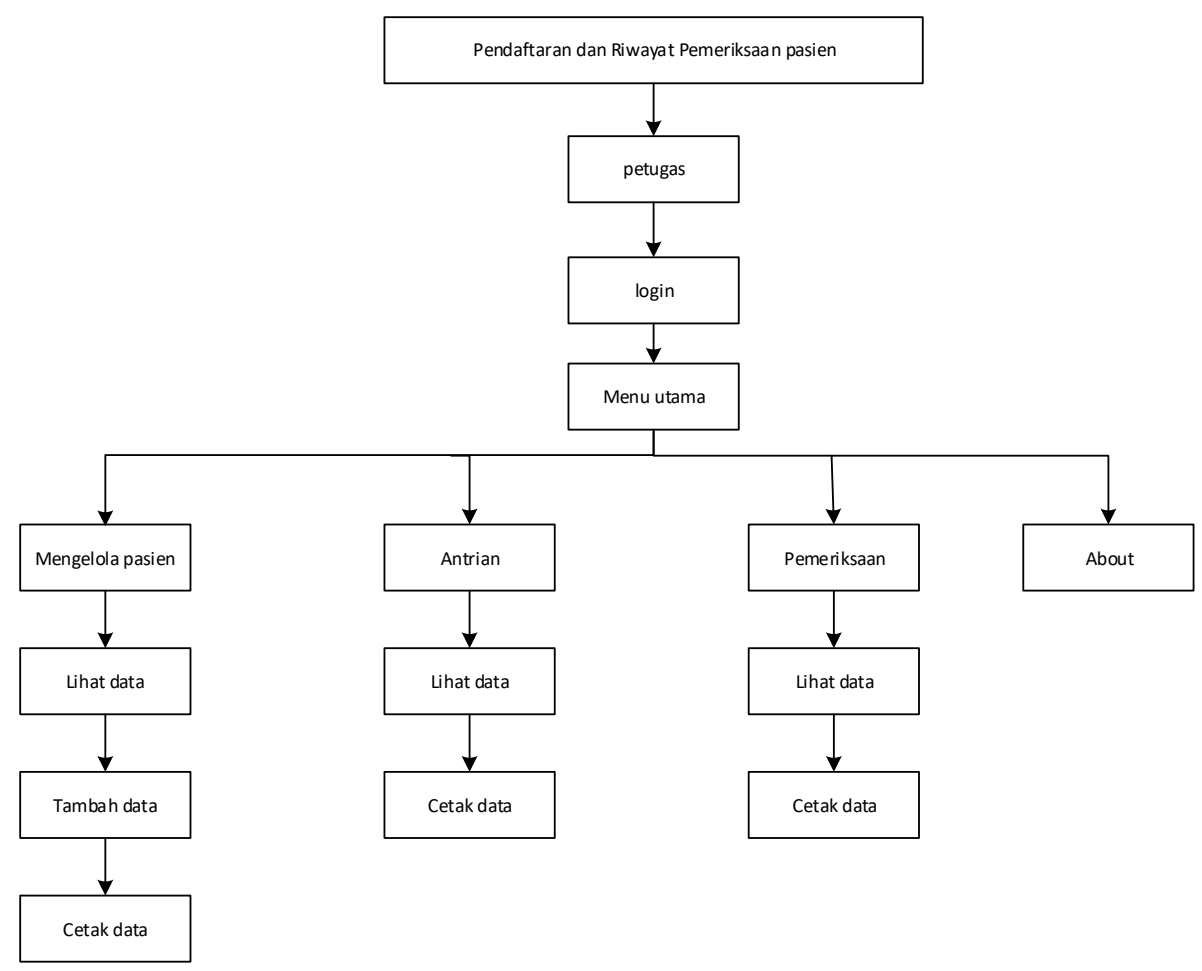

Gambar 6: Petugas

f. Perancangan Antarmuka

Berikut adalah perancangan antarmuka aplikasi pendaftaran dan riwayat pemeriksaan pada pasien di klinik.

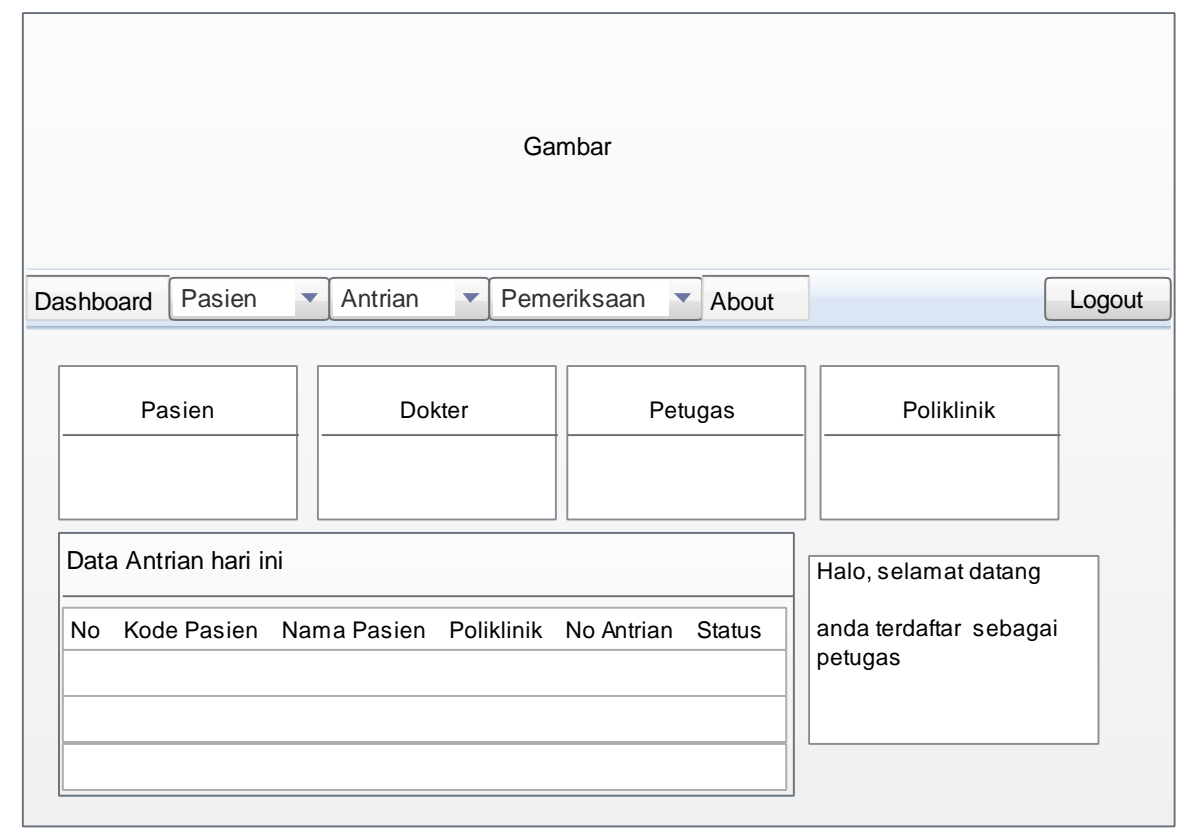

Gambar 7: Perancangan Antarmuka Petugas 
3) Implementasi

Pada tahapan ini menghasilkan bentuk awal rancangan website pendaftaran dan riwayat pemeriksaan pada pasien di klinik.

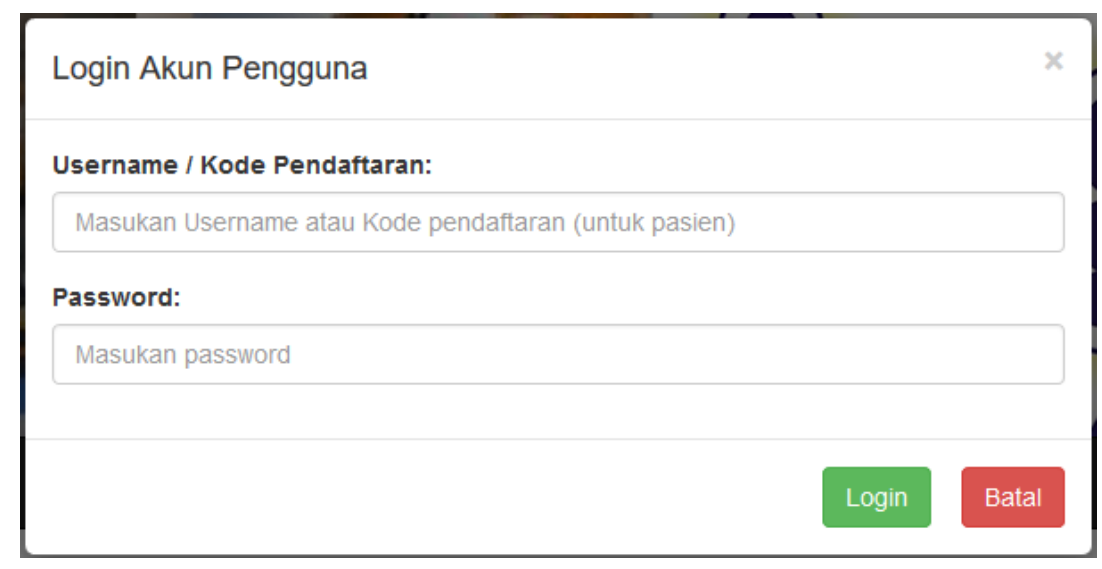

Gambar 8: Tampilan Halaman Login

4) Deployment

Pada tahapan ini membuat diagram deployment dimana untuk menggambarkan simpul atau perangkat keras apa saja apa saja yang terhubung dengan sistem yang dapat dilihat dibawah ini:

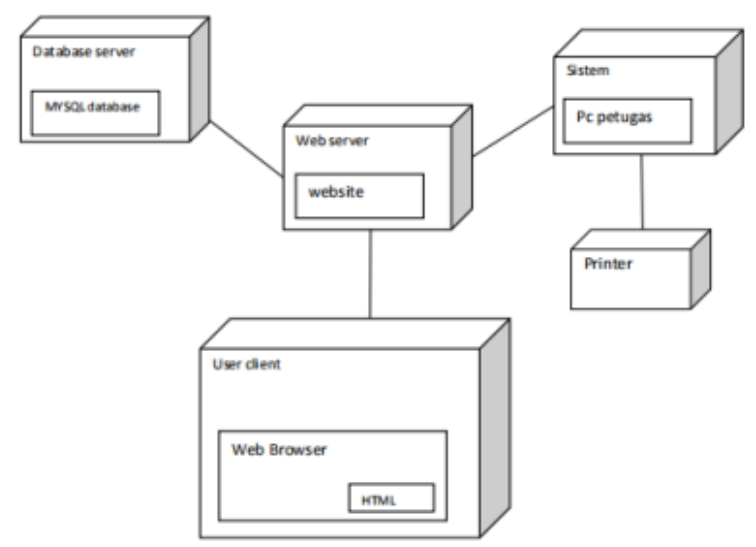

Gambar 9: Deployment

5) Pengujian

Adapun hasil pengujian disajikan dalam bentuk tabel, sebagaimana tampak pada Gambar 10. 


\begin{tabular}{|l|l|l|}
\hline \multicolumn{1}{|c|}{ Kelas Uii } & \multicolumn{1}{|c|}{ Hasil yang diharapkan } & Hasil \\
\hline $\begin{array}{l}\text { Akses halaman } \\
\text { Login }\end{array}$ & Halaman Login dapat diakses dengan baik & Berhasi1 \\
\hline $\begin{array}{l}\text { Melakukan } \\
\text { Login benar }\end{array}$ & Masuk ke menu utama & Berhasil \\
\hline $\begin{array}{l}\text { Melakukan login } \\
\text { salah }\end{array}$ & $\begin{array}{l}\text { Tidak dapat masuk kemenu utama dan kembali } \\
\text { ke halaman login }\end{array}$ & Berhasil \\
\hline Kelola pasien & $\begin{array}{l}\text { Petugas dan admin dapat menambah, melihat, } \\
\text { merubah, menghapus data pengguna, dan } \\
\text { mencetak data }\end{array}$ & Berhasil \\
\hline Kelola Antrian & $\begin{array}{l}\text { Petugas dan admin dapat melihat, merubah, } \\
\text { dan menghapus data siswa }\end{array}$ & Berhasil \\
\hline $\begin{array}{l}\text { Kelola } \\
\text { Pemeriksaan }\end{array}$ & $\begin{array}{l}\text { Petugas, admin, dan dokter dapat melihat, } \\
\text { menambah, merubah, menghapus dan } \\
\text { mencetak data } \\
\text { Pasien dapat melihat riwayat pemeriksaan }\end{array}$ & Berhasil \\
\hline Kelola Dokter & $\begin{array}{l}\text { Admin dapat melihat, menambah, merubah } \\
\text { dan menghapus data }\end{array}$ & Berhasil \\
\hline Kelola Poliklinik & $\begin{array}{l}\text { Admin dapat melihat, menambah, merubah } \\
\text { dan menghapus data }\end{array}$ & Berhasil \\
\hline Kelola Pengguna & $\begin{array}{l}\text { Admin dapat melihat, menambah merubah } \\
\text { dan menghapus data }\end{array}$ & Berhasil \\
\hline Pendaftaran & $\begin{array}{l}\text { Pasien dapat melihat dan merubah data } \\
\text { Edit Profil }\end{array}$ & $\begin{array}{l}\text { Pasien dapat melihat dan merubah data } \\
\text { Berhasil }\end{array}$ \\
\hline
\end{tabular}

Gambar 10: Tabel Hasil Pengujian

\section{KESIMPULAN DAN SARAN}

\section{A. Kesimpulan}

Kesimpulan yang dapat diambil dari penelitian yang telah dirancang adalah:

1) Pada penelitian ini berhasil merancang sebuah aplikasi pendaftaran dan riwayat pemeriksaan pasien di klinik untuk mempermudah pasien dalam mendaftar secara online dan petugas dalam mengelola riwayat pemeriksaan, dalam perancangan sistem ini menggunakan metodoligi Unified Sofware Development Process;

2) Hasil dari penelitian ini adalah berbentuk aplikasi perangkat lunak berbasis website tentang sistem informasi pendaftaran dan riwayat pemeriksaan pada pasien di klinik yang membantu klinik mempermudah penyampain informasi kepada pasien sehingga diharapkan tidak ada kesalahan informasi yang disampaikan;

3) Aplikasi memudahkan petugas dalam mencetak data yang berguna untuk memberikan informasi secara mendetail;

4) Aplikasi memudahkan dokter dalam mencetak riwayat pemeriksaan dan melakukan pemeriksaan pada pasien melalui website.

\section{B. Saran}

Peneliti berikutnya yang akan mengembangkan aplikasi ini agar sistem bisa dibuat secara Android ataupun mendukung untuk Android agar lebih mudah dalam mengaksesnya. 


\section{DAFTAR PUSTAKA}

[1] E. Y. Anggraeni dan R. Irvani, PENGANTAR SISTEM INFORMASI, I. Yogyakarta: CV. ANDI OFFSET, 2017.

[2] A. Kristanto, Perancangan Sistem Informasi dan Aplikasinya, Revisi. Yogyakarta, 2018.

[3] I. muhammad Hanif dan L. Fitriani, Perancangan Perangkat Lunak Sistem Informasi Rekam Medis Berbasis Client-Server Studi Kasus Klinik Cipanas, J. Algoritm, 2016.

[4] A. Mulyani dan F. N. Ramadhan, Rancang Bangun Sistem Informasi Penerimaan Santri Baru Di Sekolah Dasar Islam Terpadu Persis Tarogong Berbasis Web ,J. Algoritm, 2015.

[5] L. Lukmanurkarim dan A. Mulyani, Pengembangan Aplikasi Pencatatan Persediaan Obat Menggunakan Metodologi Berorientasi Objek di Apotek Nur Gesifa, J. Algoritm., 2016.

[6] R. Sinaga dan Nurhadi, Analisis Dan Perancangan Sistem Informasi Rekam Medis Pada Klinik Akper Kesdam II / Sriwijaya Garuda, J. Manaj. Sist. Inf., 2016.

[7] B. Nugroho, S. H. Fitriasih, dan B. Widada, Sistem Informasi Rekam Medis di Puskesmas Masaran I Sragen, J. TIKomSiN, 2015,

[8] A. Nugroho, Rekayasa Perangkat Lunak Berorientasi Objek dengan Metode USDP, I. Yogyakarta: C.V ANDI OFFSET, 2010.

[9] R. R. Rerung, Pemrograman Web Dasar. Yogyakarta: CV Budi Utama, 2018.

[10] HIdayat, Marlina, Utami, dan L. Dini, Perancangan Sistem Informasi Penjualan Barang Handmade Berbasis Website Dengan Metode Waterfall, 2017.

[11] H. Lalompoh, Pengembangan Aplikasi Pelaporan Kuliah Kerja Terpadu Universitas Sam Ratulangi, J. Tek. Inform., hal. 2, 2018.

[12] R. AS dan M. Shalahudin, Rekayasa Perangkat Lunak Terstuktur dan Berorientasi Objek. Bandung: Informatika Bandung, 2018. 